\title{
La muerte en el Infierno: a propósito del Hom- bre-árbol del Jardín de las Delicias del Bosco
}

\author{
Esperanza Aragonés Estella \\ Universidad de Navarra
}

\section{A mis hermanos y sobrinos}

RESUMEN. En este artículo propongo la identificación de la figura del hombre-árbol, que ocupa un lugar protagonista en el Jardín de las de Delicias, con la muerte eterna a la que se llega por el pecado de los hombres representado ampliamente en todo el espacio infernal. Dichas faltas no responden al modelo de los siete pecados capitales sino que, a pesar de inscribirse en alguna de estas categorías penales, corresponden a los males dañinos para la sociedad: Iglesia corrupta, música profana, juego y bebida, que suponen un atentado al orden social imperante. El avance a una concepción moderna del Infierno se ve en el escaso protagonismo concedido a la figura de Lucifer, arrinconado en una esquina de su reino, mientras que la muerte eterna ocupa un lugar destacado, final al que se llega por los pecados de los hombres.

Palabras clave: Bosco, Jardín de las Delicias, Hombre-Árbol, Muerte.

ABSTRACT. In this article I propose identifying the figure of the Tree-Man, who holds a leading role in the Garden of Earthly Delights, with Eternal Death, which is where the sins of mankind (widely represented in this infernal scene) lead. However, although some of the misdemeanours in the scene fit into the model of the seven capital sins, most of them actually depict wrongdoings that are harmful to society: corrupt clergymen, profane music, gambling and drinking - all of which are an attack upon ruling social order. The emergence of the modern concept of Hell is reflected in the secondary role given to the figure of Lucifer, depicted in a corner of his kingdom, whereas eternal death - the ultimate destination of sinful mankind, holds a predominant role.

Key Words: Hieronymus Bosch, Garden of Earthly Delights, Tree-Man, Eternal Death.

El tríptico del Jardín de las Delicias del Museo del Prado', corresponde a la etapa

\footnotetext{
${ }^{1}$ El tríptico fue encargado por Enrique III de Nassau y fue visto por un viajero italiano en el palacio del príncipe en 1517, un año después de la muerte del Bosco. Felipe II compró esta obra junto a otras tablas del Bosco para su propia meditación: W. S. GIBSON, "The Garden of Earthly Delights by Hieronymus Bosch: The iconography of the central panel" en Nederlands Kunsthistorisch Jaarboek, 24, (1973), pp. 4-5. Se representa en el panel central la entrega de la humanidad al pecado de la lujuria, así como en el tríptico del Carro de Heno los hombres se corrompen por otro de los grandes pecados capitales, la avaricia; pecados
}

de madurez del genial artista flamenco, Jerónimo Bosco. Se ha supuesto una obra de hacia 1500, organizada en tres tablas, en la que la primera representa la creación y el pecado original, la central el mundo entregado al pecado de la lujuria, y la tercera el castigo de esta humanidad pecadora en el Infierno. Este espacio punitivo presenta en el centro una figura blanca y casi humana cuya identificación plantea muchas dudas.

estos señalados y condenados en el Infierno desde el románico. 
La configuración híbrida en la que se mezclan un rostro humano, un caparazón como de huevo horadado por las ramas que salen de sus patas de tronco de árbol y apoyan sobre unas barquillas ha dado pie a variadas interpretaciones. Desde el Árbol del Conocimiento de Fraenger, incidiendo en su aspecto vegetal ${ }^{2}$, a la Nave de los Locos de I. Mateo por el cuerpo abierto como una nave además apoyada en barquillas ${ }^{3}$, para Yarza por el aspecto de engaño e inestabilidad el mismo diablo ${ }^{4}$, para Peñalver Alhambra el "Hombre-árbol" sería un posible autorretrato del artista asociado a la muer$t^{5}$, opinión ésta última mantenida recientemente por J.A. Ramírez ${ }^{6}$.

2 W. FRAENGER, Hieronimus Bosch, Amsterdam, 1994 (cop. 1947), pp. 44-45, aunque en algunos comentarios recuerda el color de cadáver de la figura o habla de muerte espiritual. La teoría interpretativa de este autor con respecto a la obra del Bosco, vinculandolo con una secta herética adamita: Hermanos y Hermanas del Libre Espíritu y explicando a partir de esta supuesta vinculación la obra de este artista es errónea y ha dado lugar a multitud de críticas, pero también habría que destacar que en interpretaciones parciales de las torturas infernales está muy acertado, como veremos.

3 I. MATEO GÓMEZ, El Bosco en España, Madrid, 1991 (1 $1^{\text {a }}$ ed., 1964), p. 22; a pesar de que el tema de la Nave de los Locos no corresponde a una escena infernal, si que recuerda la autora en el comentario de la figura, la palidez de la muerte en el rostro.

${ }^{4}$ J. YARZA LUACES, El Jardín de las Delicias de el Bosco, Madrid, 1998, pp. 70-72; sin embargo el Príncipe del Infierno es el monstruo devorador situado en la parte inferior derecha, identificado con los elementos propios del jerarca "a la manera del Bosco" es decir con una olla como corona y el trono sobre el que se sienta.

${ }^{5}$ L. PeÑalver AlHAMBra, Los monstruos de El Bosco, Valladolid, 2003, p. 145. Esta figura la incluye en el epígrafe de su obra titulado "El Infierno musical" y en varias ocasiones alude a un retrato del artista desesperado y melancólico: «Representaría entonces este monstruo u Hombre-árbol con los rasgos de un posible autorretrato, sino el suicidio, al menos el peor de los pecados, la desesperación...» p.146 y de nuevo: p. 154.

${ }^{6}$ J. A. RAMírez, Bosco, [Madrid], D.L. 2005, p. 21 ( esta cita me fue proporcionada por mi amigo Mikel Zuza, medievalista, a quien agradezco desde aquí su colaboración); en la presentación del libro dice que esta figura del hombre-árbol es el retrato del artista.
Para mí es la muerte del alma que trae el pecado, para ello me baso en el tono blanco que recuerda al del cadáver, opinión reforzada por el caparazón que imita una cavidad torácica con costillas, y porque los únicos elementos numinosos en el negro escenario infernal sumido en tinieblas aluden a la muerte, así el cráneo de equino al lado, que representa los sepulcros blanqueados de los hipócritas y fariseos (Mt. 23, $27)^{7}$, en una crítica a la Iglesia reforzada por los personajes eclesiásticos que le acompañan. Y el cuchillo entre dos orejas en la parte superior recordaría a los que no oyen las palabras del Evangelio y caen en el pecado, visión gráfica muy clara de aquella frase bíblica: «El que tenga oídos, oiga lo que el espíritu dice a las iglesias. El vencedor no sufrirá daño de la muerte segunda» $(\text { Ap. 2, 11) })^{8}$ y en otras citas previas con el mismo sentido (Sal.115, 6 y Mt. 11, 15) ${ }^{9}$ y

Una pena porque páginas antes sugiere una idea que bien puede concluir en la interpretación de esta figura del Infierno con la muerte eterna. Así dice en la pág. 17: «La idea de que los dos paneles laterales son una perfecta inversión el uno del otro vendría reforzada por algo que también ha pasado inadvertido y es que los principales lugares de ambos son coincidentes aunque contrapuestos: las maravillosas montañas "naturales" del Paraíso se han transmutado en pavorosos edificios "humanos" incendiados; la fuente de la vida es en el infierno un organismo híbrido (medio animal y vegetal, con cara humana) cuyas piernas se apoyan en unas inestables barquichuelas...»y añado yo: ¿que mejor correspondencia para la vida eterna en el Paraíso que la muerte eterna en el Infierno?.

${ }^{7}$ La cita completa dice así: "Ay de vosotros, escribas y fariseos hipócritas, pues sois semejantes a sepulcros blanqueados, que por fuera parecen bonitos, pero por dentro están llenos de huesos de muertos y de toda inmundicia»; esta interpretación del cráneo como monasterio está tomada de W. FRAENGER, Op. cit. (nota 2), p. 52 .

${ }^{8}$ Don Ildefonso Adeva teólogo de la Universidad de Navarra es quien me proporciona esta valiosa cita, le agradezco desde aquí su amable colaboración.

${ }^{9}$ Estas citas bíblicas y otras muchas que tienen el mismo contenido tomadas de W. FRAENGER, Op. cit. (nota 2), p. 48. Esta interpretación de las orejas es aceptada por I. MATEO, Op. cit .(nota 3), p. 22; mientras que autores como YARZA aluden al sexo masculino $O p$. 
por tanto la $M$ sería la inicial de la muerte y no aludiría a la primera letra del nombre del Anticristo: Malignus, más calificativo universal aplicado al diablo desde la Biblia, que nombre propio del falso profeta ${ }^{10}$. Personaje este raramente presente en el Infierno si no es para significarle, ocupando un puesto de majestad en el regazo de su padre Satanás ${ }^{11}$, o muy escasamente condenado por simonía. En el infierno italiano de Pisa del s. XIV, el Anticristo aparece en el círculo de los simoníacos, por el paralelismo tan frecuente que se hacía entre Simón el Mago que imitaba a Cristo y el impostor del fin de los tiempos, por lo que este último es desollado y se le saca la piel al completo, sin roturas, en clara alusión a la venta de la túnica inconsútil de Cristo ${ }^{12}$.

La personificación de la muerte en el Infierno es una redundancia tal que no es frecuente encontrarla en las visiones infernales; que yo conozca aparece tempranamente en la Puerta de Nôtre Dame de París de principios del s. XIII (Lám. 1), vista como una amazona desnuda de ojos vendados que cabalga un caballo encabritado del que

cit. (nota 4), p. 74 y PEÑALVER, Op. cit. (nota 5),p. 96; ve un símbolo de ambos sexos.

${ }^{10}$ W. S. GIBSON, Op. cit. (nota 1), p.26, n.73; donde dice que la $M$ puede aludir a Malignus el nombre dado al Anticristo en un tratado del s. XV. Esta opinión es retomada por YARZA, Op.cit. (nota 4), p.75 junto a las otras posibilidades significativas dichas por GIBSON. PEÑALVER, Op.cit. (nota 5), p.96; da la correcta identificación para la letra grabada en el cuchillo, aunque añade que esta versión no excluye la del nombre del Anticristo o príncipe de la muerte.

${ }^{11}$ Así aparece en el en el mosaico del Juicio Final de la iglesia veneciana de Torcello (sb.1100) o en el Infierno miniado del Hortus Deliciarum de Herrade de Landsberg, pintado h.1175-1185; las imágenes y estudio de estos infiernos aparecen en J. BASCHET, Les justices de l'au-delà; Rome, 1993.

12 p. 306 de J. BASCHET, Ibidem. Sobre el Anticristo en la Edad Media así como su presencia en el arte y en la literatura véase: R. K. EMMERSON, Antichrist in the Middle Ages, Seattle, cop.1981, especialmente para el paralelismo iconográfico entre Simón el Mago y el Anticristo, pp. 122-124. se descuelga un cadáver. La mujer, en femenino del latín mors-mortis, lleva unos puñales con los que acaba de matar a su víctima, descompuesta en la grupa de la montura ${ }^{13}$. Más cercano al Infierno bosquiano es la visión del Juicio Final de Van Eyck (c. 1430) (Lám. 2) donde un esqueleto combado forma una cavidad que constituye la bóveda del Infierno. La visión es gráfica y clara y la mirada putrefacta de la calavera informa al espectador de la cruenta muerte del alma. La figura del Jardín de las Delicias tiene rostro masculino en un cuerpo cadavérico, algo desconcertante para identificar a la muerte, sino fuera porque en holandés la palabra muerte es de género masculino o femenino: dood, y el Bosco eligió el rostro de un hombre para representarla (Lám. 3). La figura bosquiana es tan

\footnotetext{
${ }^{13}$ La correcta identificación de esta dovela parisina y de sus réplicas en Amiens y Reims, la hizo en 1939 E. PANOFSKY en Estudios de iconología, en el capítulo dedicado a Cupido el ciego, p. 155. Años más tarde W. SAÜERLANDER en La sculpture gothique en France, París, 1972 , p. 132; identifica esta amazona con el $4^{-}$ Jinete del Apocalipsis y al lado otro caballero apocalíptico que para este autor lleva una balanza (yo veo un arco). El problema de esta identificación es que sirvió para ver el mismo cuarto jinete en la Puerta del Juicio de Tudela, tal como hicieron M. MELERO; "Aproximación a la iconografía del $4^{\circ}$ Jinete del Apocalipsis" en Lambard: Estudis d'art medieval, (1986), pp. 125-128, y muy a mi pesar S. MORALEJO; "Modelo, copia y originalidad en el marco de las relaciones artísticas hispano-francesas (siglos XI-XIII)" en Actas del $V^{0}$ congreso CEHA. Sección 1a, Barcelona, 1984, p. 100-101, este autor ve la muerte en el cuarto jinete apocalíptico. Todavía en 1993 J. BASCHET, Op. cit. (nota 10), p.169, continúa la idea de Sauerländer y dice que son jinetes del Apocalipsis o una cabalgada de muertos las figuras esculpidas en París. Los 4 jinetes de este texto de san Juan son signos premonitorios del fin de los tiempos, ni humanos ni mortales, tampoco pecadores y por tanto sin lugar de condena en el infierno. Su interpretación doctrinal está en la línea de verlos como castigos que envía Cristo, el primer jinete sobre montura blanca, por la iniquidad del mundo. De acuerdo con esta interpretación también resulta difícil ver al Anticristo en el Infierno, a pesar del clima de terror y miedo a este personaje que se vivía en los tiempos en que se pintó esta tabla del Jardín de las Delicias, por la corrupción de la Iglesia y el Papado.
} 
expresiva que fue imitada para representar el Infierno en un grabado alemán protestante de fines del s. XVI (Lám. 4). En este dibujo, el monstruo abre la boca en una alusión a las mandíbulas del Infierno para mostrar a monjes comiendo y bebiendo ante una mesa y recibe al Papa cubierto con tiara y con las llaves pontificias en la mano. Detrás ramas secas de un árbol llenas de diablos que alimentan el fuego donde se cocinan ricos manjares para los eclesiásticos, el monstruo apoya uno de sus pies sobre un rico almirez, en lugar de la barca del Bosco, y se sienta sobre una falsa indulgencia llena de sellos ${ }^{14}$.

La Biblia está llena de referencias a la muerte identificada con el Infierno, entre las más claras estarían las del texto de Job 38, 17: « ¿Se te han mostrado las puertas de la Muerte? ¿has visto las puertas del país de la Sombra?» o el texto apocalíptico 20, 1314: "Y el mar devolvió los muertos que guardaba, la Muerte y el Hades devolvieron los muertos que guardaban, y cada uno fue juzgado según sus obras. La Muerte y el Hades fueron arrojados al lago de fuego -este lago de fuego es la muerte segunda-, y el que no se halló inscrito en el libro de la vida fue arrojado al lago de fuego". Hay otras citas que ven en el pecado la muerte del alma, y en la resurrección de Cristo la redención salvífica, además de las presentes en el Génesis a raíz del pecado original, están otras como la del Libro de la Sabiduría 2, 24: «más por envidia del diablo entró la muerte en el mundo / y la experimentan los que le pertenecen ${ }^{15}$.

\footnotetext{
${ }^{14}$ Reproducido en E. y J. LEHNER, Picture books of devils, demons and witchcraft, New York, 1971, p. 166, Lám. 232.

${ }^{15}$ Esta cita fue utilizada por los primeros exégetas de la Biblia como base de su teoría de que en la envidia estuvo el origen del mal y el pecado, más que en el orgullo; idea estudiada y formulada por I. Ma SANS, La envidia primigenia del diablo según la patrística primitiva, Burgos, 1963. La explicación definitiva la dio san
}

San Agustín a partir de estas citas y otras muchas identifica al diablo con el príncipe de la muerte en su obra Sermones y en las Anotaciones al Libro de Job ${ }^{16}$. La doctrina está formulada y los eclesiásticos convierten en imágenes o en textos de devoción las enseñanzas de la Iglesia. Desde el tímpano románico de la catedral de Jaca, en cuyos dos leones enfrentados se oponen dos significados distintos del animal, el de Cristo y el del Infierno. Y ante la visión un tanto críptica de la portada las inscripciones recuerdan el valor ejemplarizante de las imágenes: «El león sabe respetar al que se prosterna a sus pies, y Cristo al que le invoca. Hollando el Imperio de la muerte, [Cristo] es un poderoso león» o el texto del dintel: "Si quieres vivir tú que estás sujeto a la ley de la muerte, ven aquí suplicante, desechando los placeres venenosos. Limpia tu corazón de pecados para no morir de una segunda muerte». O el responso rezado en el Oficio de Difuntos: "Libera me, Domine, de morte eterna in die illa tremenda quando celli mouendi sunt et terra». Sólo unos años más tarde que fuera pintado el tríptico del Jardín de las Delicias, escribe el Maestro Venegas la Agonía del tránsito de la muerte (1537) en la que diferencia tres vidas y tres muertes consiguientes, identificando la tercera con el infierno: "La tercera vida es la vida de gloria, a la cual se contrapone, la muerte de la gehenna o del infierno, que es la carencia perpetua de la divina visión; a la cual muerte acompaña la pena sensual y el tormento de ánima en los hombres adultos" y más adelante: «Estas tres muertes se reducen a dos: que es muerte del cuerpo y muerte espiritual del ánima; porque a la muerte segunda de culpa sigue la muerte tercera,

Agustín quien vinculaba estrechamente ambos pecados: El diablo es soberbio y envidioso, en De civitate Dei, 1, 14, c.3.

${ }^{16}$ Patrología Latina (edición en CD-ROM, 19931995), para Sermones de Scripturis, col. 0823 y para Annotationes in Job, col. 0874. 
así como a la vida de gracia consigue la vida de gloria»" ${ }^{17}$.

La visión de la muerte en el Infierno ocupando un lugar protagonista permite una nueva lectura de este espacio claramente catequizante en la que se da valor a los pecados dañinos para la sociedad frente a la visión arquetípica de los pecados capitales. La muerte eterna la recibe el caballero condenado por profanador y no por hombre de armas (la guerra es un mal necesario), al que se le prepara la horca como a un delincuente común. La Iglesia vista como un cráneo de caballo, en crítica alusión siguiendo las palabras de san Mateo y de donde cuelga la llave de San Pedro que identifica el lugar ${ }^{18}$. Que curioso que este espacio esté identificado por medio de imágenes visuales de citas bíblicas, el libro por excelencia de la Iglesia. Además en un extremo del infierno aparece una cerda con toca de abadesa que falsifica reliquias a cambio de favores amorosos ${ }^{19}$.

Le sigue la condena a la música profana $^{20}$ y se acompaña más abajo del juego

${ }^{17}$ Agonía del tránsito de la muerte, cap. III: De la división de la muerte; esta cita, así como interesantes anotaciones del texto me ha sido proporcionada por el don Ildefonso Adeva, a quien le agradecemos su colaboración.

${ }^{18}$ I. GOMEZ DE LIAÑO, "La variedad del mundo o el Tríptico de la Creación" en El Bosco y la tradición pictórica de lo fantástico, Madrid, 2006, p. 213, donde dice: “La llave alude a las llaves que Jesús confió a Pedro para que pudiera abrir y cerrar las puertas del reino de los cielos (Mateo 16, 19) y la vara de la que la llave está suspendida, a la caña del pescador, símbolo del poder redentor que el Salvador confirió a los Apóstoles".

${ }^{19}$ I. MATEO GÓMEZ, Op. cit., (nota 3), p. 25. Estoy de acuerdo con esta opinión frente a los que ven en este pie cortado un castigo de la justicia de la época.

${ }^{20}$ W. FRAENGER, Op. cit.(nota 2), p.57; de nuevo nos da una valiosa interpretación de la figura que camina con un huevo sobre su espalda y se apoya en un bastón sobre el organistrum, al ver la eternidad de su castigo, ya que si fuera capaz de pasar el huevo por la espalda y mantenerlo erguido en la cabeza pasaría inmediatamente del Infierno al Cielo, pero esto para un hombre apoyado en una muleta es imposible. La de azar. El vino y el juego engendran violencia y muerte y traen graves males a la sociedad. La esposa y su marido enredados en el juego, porque la fémina desnuda identificada en algunas publicaciones con una diosa del azar por el dado en la cabeza y su desnudez o una prostituta en otros casos, es una esposa como ya viera I. Mateo, autora que en más de una publicación ha destacado la jarra y la vela como propios de la iconografía matrimonial siguiendo el ritual de las bodas ${ }^{21}$. El marido de la condenada estaría en la parte de abajo, desnudo como su pareja, ya que está suficientemente identificado con las galochas que calza el diablo que le castiga ${ }^{22}$, calzado este que es propio de la moda en que fue pintado el cuadro pero que forma parte igualmente del ritual y de la imaginería del matrimonio, ya que según Van Gennep tiene un sentido específicamente sexual y fecundador ${ }^{23}$. El Bosco lo usó para identificar a un matrimonio en la escena de la ira en la Mesa de los pecados capitales; previamente acompañaba a los esposos en el cuadro de Van Eyck, El matrimonio Arnolfini (1434) y Hugo van der

peculiar visión del castigo eterno genialmente interpretado por el Bosco se enriquece por el instrumento donde se apoya, ya que el andar oscilante de este hombre recuerda el movimiento acompasado de la música.

${ }^{21}$ I. MATEO GÓMEZ, "El grupo de los jugadores en el "Jardín de las Delicias" del Bosco" en Archivo Español de Arte, 127, (1959), pp. 253-256.

${ }^{22}$ El término está tomado de C. BERNís MADRAZO, Trajes y modas en la España de los Reyes Católicos, Madrid, 1978, p. 30-31, quien dice que eran un calzado de la moda francesa y flamenca del tercer cuarto del s. $\mathrm{XV}$, mientras que un zapato semejante pero de suela de corcho, los alcorques, eran tradicionales de España.

${ }^{23}$ A. VAN GENNEP, Manuel de folclore francais contemporain, París, 1980 (reimp. de la ed. original de 1946), pp. 406-413; no alude expresamente a las galochas sino que habla del calzado en general como propio del ritual de la pareja; la pintura flamenca fecunda en símbolos convierte los zuecos junto a otros objetos en imagen del matrimonio porque era el calzado de moda en aquella época. 
Goes lo usó en el Tríptico Portinari (c. 1476) identificando al matrimonio sagrado ${ }^{24}$.

Satanás como príncipe del Infierno o de la Muerte, "coronado y entronizado" ocupa una esquina de su reino y devora a pecadores como el glotón que vomita, el avaro que defeca sus monedas ${ }^{25}$, la orgullosa reflejada en el espejo de un diablo con brazos de ramas secas ${ }^{26} \mathrm{o}$ el perezoso que

${ }^{24}$ E. PANOFSKY, Los primitivos flamencos, Madrid, D.L.1988 (cop.1953), p. 203; dice que los zuecos en el suelo de la estancia en la pintura del matrimonio Arnolfini, y en la de Hugo van der Goes aluden a la advertencia de Yahvé en el monte Sinaí a Moisés diciéndole que se descalce porque está en tierra sagrada, lo que en estas pinturas flamencas indicaría respeto a la divinidad. Esta interpretación del calzado fue retomado y aceptado por E. HALL, The Arnolfini betrothal: medieval marriage and the enigma of Van Eyck's double portrait, UCP, 1994, pp. 106-112. De acuerdo con el rito matrimonial enseñado por Gennep y visto que tanto la jarra como la vela caracterizan a los esposos en la pintura flamenca veo que los zuecos forman parte de la iconografía matrimonial tanto de la pareja profana como de la sagrada.

${ }^{25}$ L. K. LITTLE, "Pride goes before avarice: Social change and the vices in latin christendom" en The American Historical review, 76, (1971), pp. 16-49; es el primero que yo conozca que cita la figura de los monos defecando monedas en las marginalias de los manuscritos (figs. 10 y 11 de su artículo). Autores posteriores como C. GAIGNEBET Y J. D. LAJOUX, Art profane et religion populaire au Moyen Age, París, 1985; B. MARIÑO, "Sicut in terra est in inferno" en Archivo Español de Arte, 246, (1989), p. 161; citan imágenes anteriores del gótico europeo como las de Burgos (esta última informada por Mariño) Amiens, Estrasburgo y Goslar. Todas reproducen el castigo del avaro, salvo la figura del personaje que defeca una moneda en el Palacio del Kaiser de Goslar quien según las noticias de R. MELLINKOFF, Averting demons: The protective power of medieval visual motifs and themes, Los Ángeles, 2004, $\mathrm{t}$. I, p. 139 y t.II, Lám VI.83; el hombrecillo que defeca oro traerá buena suerte a Goslar; interpretación basada en una inscripción de una moneda que reproduce la escultura.

${ }^{26}$ La orgullosa ve su imagen reflejada en el espejo tal como el Bosco había caracterizado a esta pecadora en la Mesa de los 7 pecados capitales. El espejo que indica la presunción y vanidad de la pecadora se convierte en el siglo $\mathrm{XV}$ en un atributo de este pecado más que de la lujuria, tal como había caracterizado dormita en una cama. Pecados capitales que suponen una calificación penal menor que los vicios protagonistas de la tabla que son además delitos, por ello las referencias a la justicia de la época como la mano cortada del jugador ${ }^{27} \mathrm{o}$ el tahúr decapitado y con los ojos vendados como si fuera un delincuente. Esta visión del infierno dirigida a pecadores concretos tiene sus orígenes en los infiernos del s. XIII que plasman en sus portadas los males de la época de acuerdo con las advertencias del Papa Gregorio IX (1227-1241), faltas como la blasfemia, adulterio, homosexualidad, herejía... condenadas y denunciadas en portadas del gótico hispano como Tudela y la más tardía de Toro (Zamora) ${ }^{28}$. Varias décadas después Dante organizaba geográficamente el Infierno en la Divina Comedia y ocupaba sus círculos con las faltas más graves para la sociedad de su tiempo. Círculos concéntricos ocupados por pecados cada vez más dañinos que terminaban en los traidores situados junto al mismo Lucifer. El modelo del Septenario pasaba al Purgatorio, un espacio expiatorio de los pecados con duración temporal y no eterna. El Bosco heredero del mundo medieval, pinta en el Infierno los males de la época con especial atención

desde el románico a las mujeres que pecaban por el sexo.

${ }^{27}$ W. FRAENGER, Op.cit. (nota 2), p. 59; donde dice que el castigo es doble por perjuro, en el gesto de juramento de la mano y jugador por la mano cortada sobre la bandeja.

${ }^{28}$ La novedosa concepción del Infierno en el s. XIII receptora de nuevas fórmulas eclesiásticas sobre el pecado y su castigo desde el Concilio de Letrán (1215) y la difusión y obligación de cumplir estos cánones por parte de la sociedad cristiana impuesta por Gregorio IX, inspira un tipo de iconografía en la que se presta mayor atención al pecador y las circunstancias específicas en que se comete la falta lo que provoca una iconografía del pecador más detallada y personalizada. Las faltas aún pudiendo adaptarse al modelo genérico de los pecados capitales pasan de tener una representación abstracta e impersonal a convertirse en denuncias de los males de la época, verdadera lacra para la "paz social" deseada. 
a la Iglesia corrupta e hipócrita en un clima de denuncia previo a la Reforma protestante. Sin embargo el avance a una concepción moderna del Infierno se ve en el escaso protagonismo concedido a la figura de Lucifer, arrinconado en una esquina de su reino, mientras que la verdadera protagonista es la figura de la muerte eterna a la que se ha llegado por el pecado de los hombres.

De la muerte física y su aspecto macabro, tema de representaciones artísticas coetáneas en cuadros, esculturas y pinturas murales con valor admonitorio, el Bosco pasa a la muerte eterna con valor definitivo.

La concepción del Infierno en el Jardín de las Delicias, poniendo el acento sobre la maldad de los hombres y reduciendo la figura de Satanás, se consigue plenamente en el mismo espacio de una tabla pareja, el Carro de Heno, en la que desaparece la figura satánica y el Averno es una torre construida ladrillo a ladrillo con los pecados de los hombres ${ }^{29}$.

${ }^{29}$ W. S. GIBSON, El Bosco, Barcelona, 1993 (traducc. de la $1^{\underline{a}}$ ed. 1973), pp. 74-75; es el que sugiere esta idea a partir de una visión de san Gregorio del cielo, donde las casas se construyen con las aportaciones de las almas caritativas; mientras que el Bosco pudo haber concebido esta torre infernal construida desde la avaricia, falta denunciada en la tabla central del conjunto. Esta idea del espacio infernal no es la única semejanza de ambas tablas, también en el Carro de Heno aparece el caballero sacrílego montado ridículamente sobre una vaca y con un cáliz en la mano o el diablo cazador que lleva su presa colgando, travestido en el Jardín de las Delicias por un conejo, en una visión sarcástica del mundo al revés. Para esta última escena véase: I. MATEO GÓMEZ, “El conejo cazador del "Jardín de las Delicias" del Bosco y una miniatura de siglo XIV" en Archivo Español de Arte, noำ178, (1972), pag. 166.

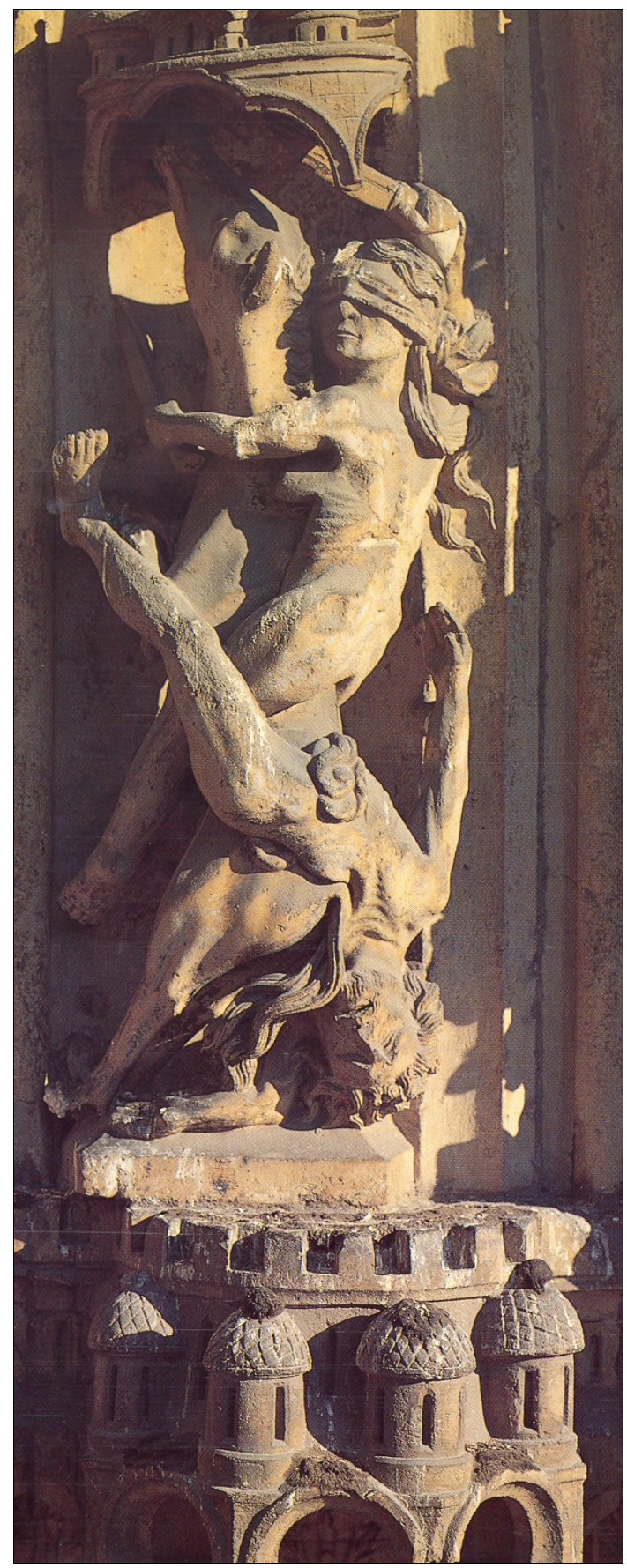

- Lám. 1. París, catedral de Nôtre Dame, fachada occidental, ppios. s. XIII. Detalle: la Muerte. (Imagen de A. ERLANDE-BRANDENBURG, Nôtre Dame de Paris,París, cop. 1997, p. 145) 


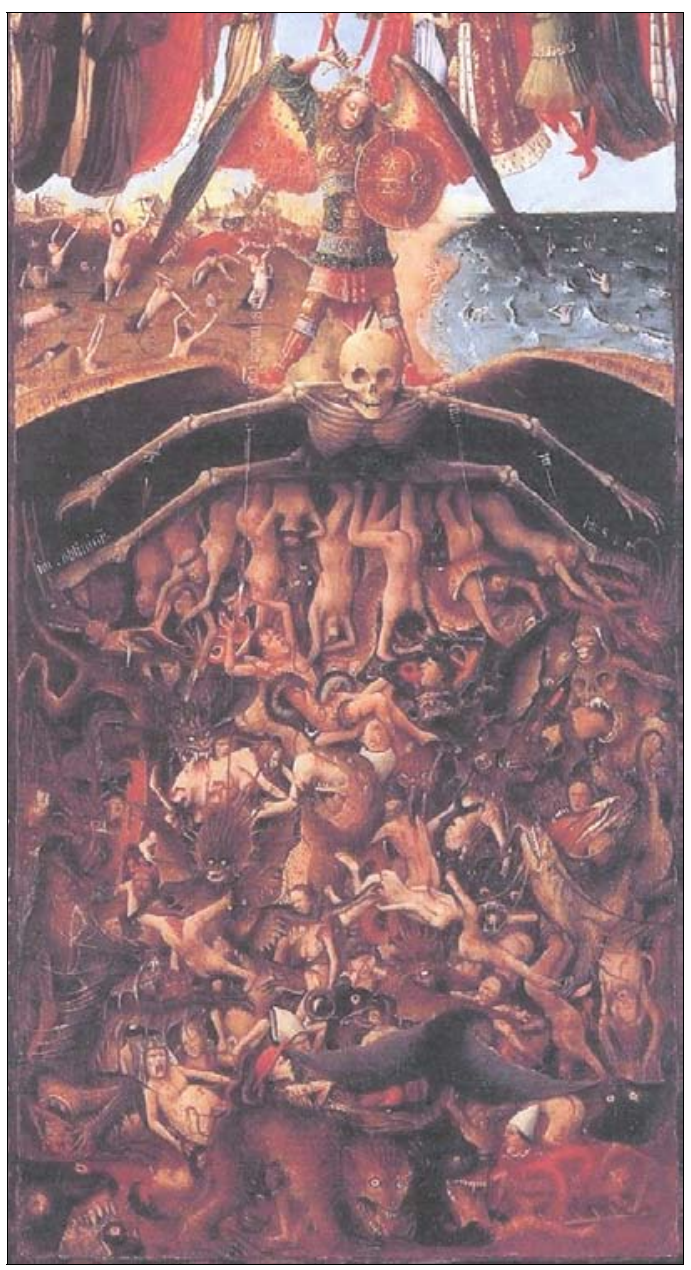

- Lám. 2. Jan van Eyck. El Juicio Final, c. 1430. Óleo sobre lienzo, trasladado desde la madera, 56,5 x 19,7 cm. New York, USA, The Metropolitan Museum of Art.

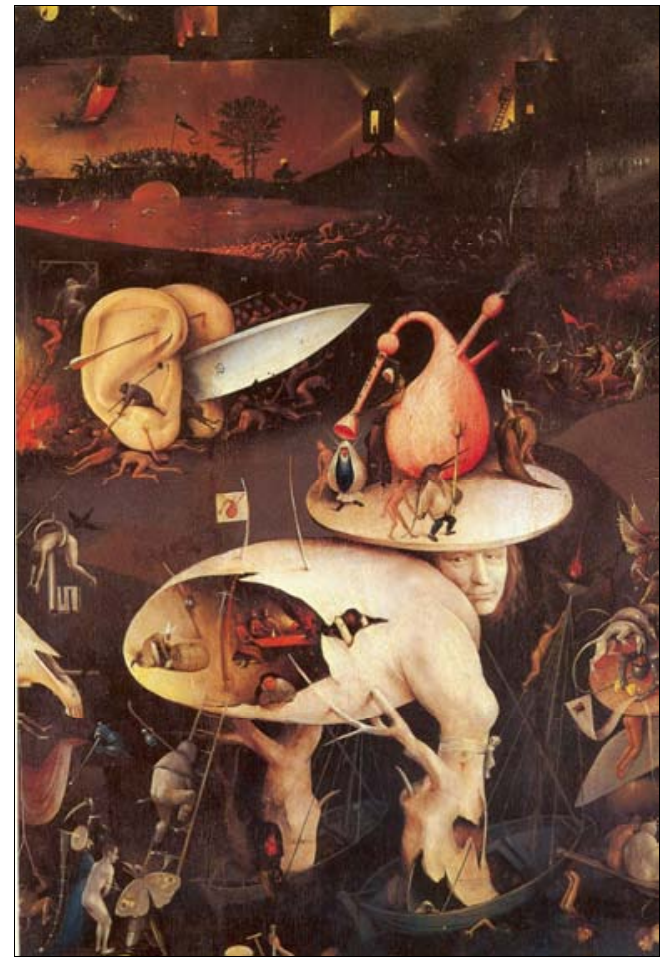

- Lám. 3. El Bosco, El Jardín de las Delicias, c. 1500. Óleo sobre tabla, 220 × $195 \mathrm{~cm}$. Madrid, Museo Nacional del Prado, cat. № 2823.

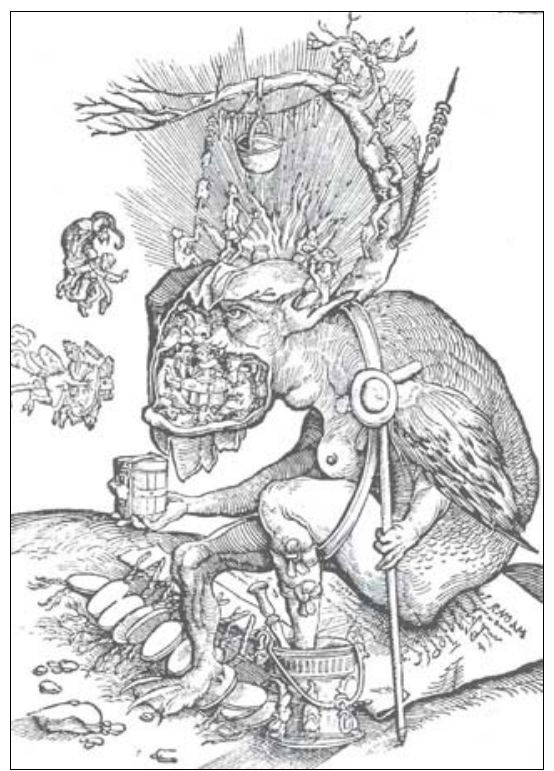

- Lám. 4. Infierno, fines del s. XVI. Grabado alemán. (Imagen de E. y J. LEHNER, Picture books of devils, demons and witchcraft, New York, 1971, p. 166, Lám 232). 